Special Issue of the 6th International Congress \& Exhibition (APMAS2016), Maslak, Istanbul, Turkey, June 1-3, 2016

\title{
High Energy Ball Milling of YAG Powders: Sintering Properties and Microstructural Evaluation
}

\begin{abstract}
A. OzER* And O.B. KiliC
Cumhuriyet University, Department of Metallurgical and Materials Engineering, 58140, Sivas, Turkey

Outstanding properties of sintered ceramics due to lower sintering temperatures and smaller grain sizes are of much attention to many researchers. In this study, YAG phase was formed successfully with mechanical activation of powder mixtures by high energy ball milling of powders at different speeds. The powders were compacted and sintered at three different temperatures to evaluate the sintering density, phase formation and grain formation. It was found that increasing activation time, which agitates the powder mixing more accurately, has led to an increase in the relative density, as compared to non-activated samples, sintered at same temperatures. Up to $95 \%$ ot the theoretical density were reached, indicating the partial liquid phase formation of Y-A related phases. YAG phase formation and crystallite size were evaluated using XRD and Debye-Scherrer formula. The studies of grain size and surface morphology were conducted using SEM. Since the mechanical activation of ceramic powders occurs by fragmentation and crack propagation, by brittle fracture of powders, the main mechanism of reduction of sintering temperature can be concluded to be the decreasing grain size, as well as the increasing strain on fine powder grains.
\end{abstract}

DOI: 10.12693/APhysPolA.131.329

PACS/topics: $81.20 . \mathrm{Ev}$

\section{Introduction}

Yttrium aluminum garnet (YAG) material has an increasing demand to be used as scintillator and solid-state laser host, due to its excellent optical, mechanical, chemical and thermal properties [1]. YAG has a cubic structure named garnet $[1,2]$. YAG single crystals are generally obtained by the Czochralski method. However, YAG single crystals are very expensive and it is difficult to produce large size YAG single crystals. For the last decade, the efforts have been attempted to synthesize transparent poly nanocrystalline YAG ceramics [2-4]. YAG laser also has a variety of applications, including medical treatment $[4,5]$. Besides, the properties may be improved by adding lantanides and actinides, such as erbium and neodymium [5-7], into yttria-alumina system. YAG has also such application areas, as ceramic coating material, sprayed in powder form [7-9], due to its high temperature resistance.

In this study, planetary ball milling of the powders of $\mathrm{Y}_{2} \mathrm{O}_{3}, \mathrm{Al}_{2} \mathrm{O}_{3}$ was applied with increasing addition of tetraethylorthosilicate (TEOS) as $\mathrm{SiO}_{2}$ source, to be used as sintering aid. The ball milling was applied to increase the strain energy in powders, as well as to reduce the particle size and to decrease the sintering temperature of YAG phase, which is over $1700^{\circ} \mathrm{C}$ in the literature.

\section{Materials and methods}

$\mathrm{Y}_{2} \mathrm{O}_{3}$ and $\mathrm{Al}_{2} \mathrm{O}_{3}$ powders were purchased from SigmaAldrich GmbH, Germany, with an average particle size

*corresponding author; e-mail: alifull@gmail.com of $1-3 \mu \mathrm{m}$, as given by MSDS paper. $\mathrm{SiO}_{2}$ was used as sintering aid which was obtained from the TEOS binder (Sigma-Aldrich GmbH, Germany). TEOS was also used as pelletizing binder and sintering aid. $\mathrm{SiO}_{2}$ was produced in-situ during the calcination. The ball milling was conducted at $600 \mathrm{rpm}$ within the periods of $60 \mathrm{~min}$ and $180 \mathrm{~min}$ following a procedure of $20 \mathrm{~min}$ of milling to left and right and 5 min of cooling cycles, it each interval. The dispersing medium was ethanol and TEOS was added into mixtures in appropriate amounts to produce 0.1 , 0.3 and $0.5 \mathrm{~mol} . \% \mathrm{SiO}_{2}$ content. Then the powders were collected and dried in mortar to obtain uniform mixtures.

The calcination was carried out under static air in an electric furnace at $850^{\circ} \mathrm{C}$ for $2 \mathrm{~h}$ with a ramping and cooling rate of $5^{\circ} \mathrm{C} \mathrm{min}^{-1}$. Thus the YAG, YAM and YAP phases were fabricated. Phase formation was also studied by means of XRD with $\mathrm{Cu} \mathrm{K} \alpha$ monochromatic radiation at $1.5408 \AA$, at step size of 0.05 and at step time of $0.25 \mathrm{~s}$, between $20^{\circ}-80^{\circ}(2 \theta)$. Scanning electron microscopy (Mira3XMU ${ }^{\circledR}$ FEG-SEM Tescan, CZ) was employed to study the powder morphology and particle/grain size.

The powders were then uniaxially pressed at $60 \mathrm{MPa}$ in a lab made hydraulic press and mold. The pellets had the dimensions of $3 \mathrm{~mm}$ in height and $13 \mathrm{~mm}$ in diameter. The pellet sizes were measured prior to sintering, to find the relative green density. The green density was found to be around $56 \%$ of theoretical density, calculated from the powder crystal densities by rule of mixtures. The pellets were sintered at $1500^{\circ} \mathrm{C}$ for $4 \mathrm{~h}$ with a ramp rate of $5^{\circ} \mathrm{Cmin}^{-1}$. The furnace was cooled down to RT by $10^{\circ} \mathrm{C} \mathrm{min}^{-1}$ to avoid possible thermal cracks. The sintered samples from either pure, $60 \mathrm{~min}$ or $180 \mathrm{~min}$ ball milled powders were evaluated by XRD, SEM to specify the phase formation and the grain morphology, 
respectively. The sintering density was evaluated by Archimedes' rule of immersion in water to find the density related to mixed powder crystal densities, named as relative density.

\section{Results and discussion}

Figure 1 shows the particle morphology and the phase formation after mixing and ball milling for $1 \mathrm{~h}(\mathrm{a}-\mathrm{c})$ and $3 \mathrm{~h}(\mathrm{~d}-\mathrm{f})$; calcination at $850^{\circ} \mathrm{C}$ for $1 \mathrm{~h}$ of ball milled powders $(\mathrm{g}-\mathrm{i})$ and for $3 \mathrm{~h}$ of ball milled powders $(\mathrm{j}-\mathrm{l})$, by increasing TEOS $/ \mathrm{SiO}_{2}$ content from $0.1 \mathrm{~mol} \%$ to $0.5 \mathrm{~mol} . \%$, respectively, as illustrated in SEM images.

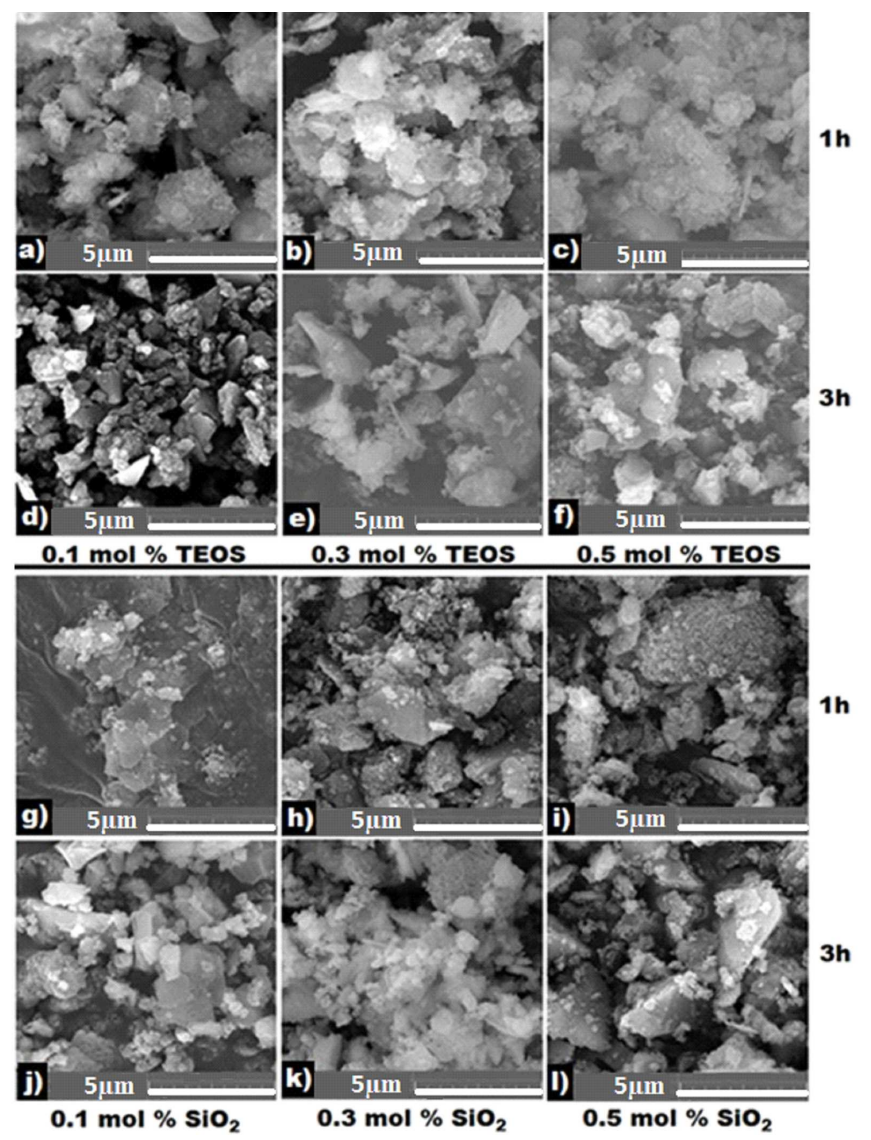

Fig. 1. SEM-SE images of $(\mathrm{a}-\mathrm{c}) 1 \mathrm{~h}$ ball milled powders before calcination, $(\mathrm{d}-\mathrm{f}) 3 \mathrm{~h}$ ball milled powders before calcination, (g-i) $1 \mathrm{~h}$ ball milled and calcined powders, (j-l) $3 \mathrm{~h}$ ball milled and calcined powders.

The results have shown that the increasing ball milling time decreases the particle size, leading to increase in specific surface area after calcination. The powders were ground to finer particles of $200-400 \mathrm{~nm}$ in size after 180 min of ball milling. Phase formation was evident, as tiny mesh-shaped rectangles with grain boundary formations of Y-A related phases, appear after calcination. Grains with larger grain boundary areas were sintered to higher relative density after sintering, compared to 60 min ball milled powders. The EDX results also confirm the formation of Y-A phases.

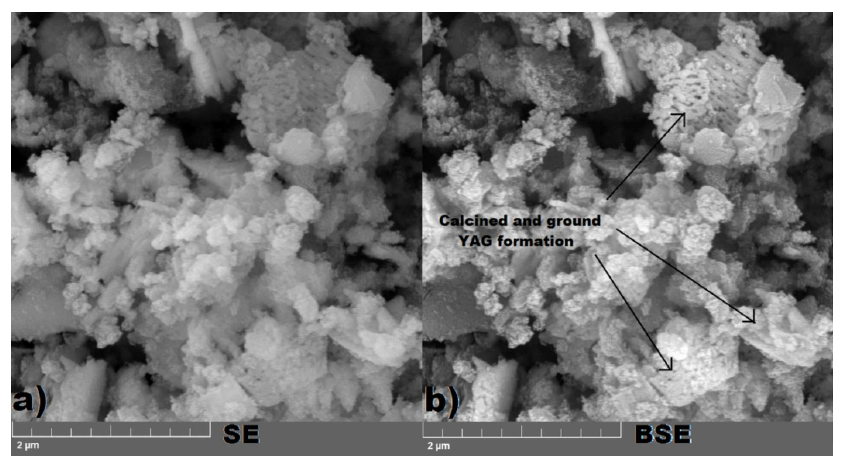

Fig. 2. (a) SEM SE imaging of $3 \mathrm{~h}$ ball milled and calcined YAG powders with added 0.3 mol.\% of $\mathrm{SiO}_{2}$; (b) BSE image.

The SEM (SE-BSE) images of $0.5 \mathrm{~mol} \% \mathrm{SiO}_{2}$-added calcined YAG ceramic is shown in Fig. 2 to demonstrate, using compositional imaging (BSE), the phase formation apparent from the contrast areas which are related to different crystal structures. These phases are thought to be due to sintering by neck formation and solid state reaction. The main attention should be kept on $\mathrm{SiO}_{2}$ content, which will also favor the transient liquid phase formation at grain boundaries, at temperatures higher than $1450^{\circ} \mathrm{C}$. The YAG phase plaques can be seen especially in Fig. 2b with compositional image (BSE), as indicated by arrows showing the calcined and ground YAG phases. The higher brightness in SEM-BSE imaging relates to higher crystal density while others seem to be greyish or black.

Figure 3 shows the XRD patterns of three samples, powder mix (Fig. 3a), 60 min planetary ball milled (Fig. 3b) and $180 \mathrm{~min}$ planetary ball milled powders (Fig. 3c) after calcination at $650^{\circ} \mathrm{C}$. As the strain energy induced onto the powder grains increased by increasing the ball milling time, the formation of $\mathrm{Y}-\mathrm{A}$ phases was favored, in accordance with SEM images (Fig. 2a-b), due to increasing local impact statistics. The heat increase can also allow the formation of more $\mathrm{Y}$-A phases.

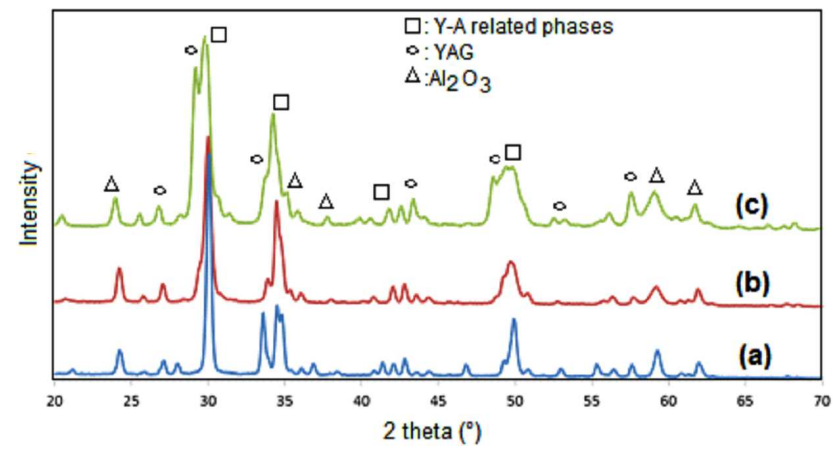

Fig. 3. XRD pattern of $0.5 \mathrm{~mol} \% \mathrm{SiO}_{2}$-added calcined powders. (a) Powder mix after calcination, (b) powders after $1 \mathrm{~h}$ of ball milling and calcination, (c) powders after $3 \mathrm{~h}$ of ball milling and calcination. 
The formation of new Y-A phases (such as YAG, YAP, YAM) has resulted in the decrease of $\mathrm{Y}$ and $\mathrm{A}$ peak intensities. Even after $180 \mathrm{~min}$ of milling (Fig. 3c), the formation of YAG and some deficient YAP, YAM phases are seen in XRD pattern. While the YAG and related phases were forming, alumina and yttria peak intensities have decreased due to combining of the yttria and alumina phases (Fig. 3a and b). The intensities of peaks of $\mathrm{Y}$ and $\mathrm{A}$ phases go down and other peaks have disappeared [10]. After $3 \mathrm{~h}$ of planetary ball milling, the powders formed a high amount of Y-A phases, which is believed to turn into YAG and other deficient phases, after sintering cycle with the aid of $\mathrm{SiO}_{2}$.

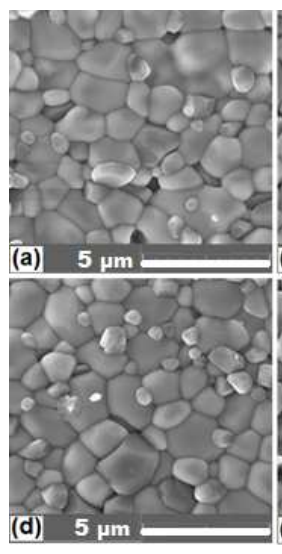

$0.1 \mathrm{~mol} \% \mathrm{SiO}_{2}$
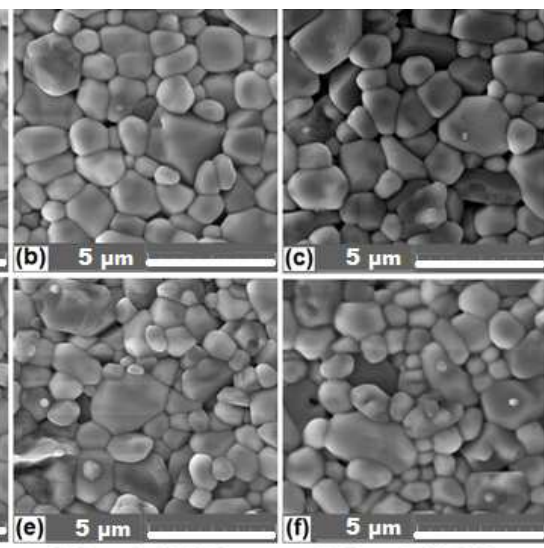

$0.3 \mathrm{~mol} \% \mathrm{SiO}_{2}$

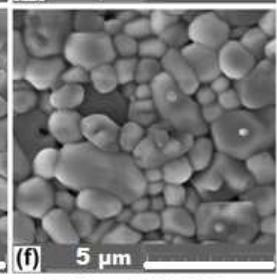

$0.5 \mathrm{~mol} \% \mathrm{SiO}_{2}$
Fig. 4. SEM-SE images of $(\mathrm{a}-\mathrm{c}) 1 \mathrm{~h}$ ball milled and sintered samples; (d-f) $3 \mathrm{~h}$ ball milled and sintered samples with increasing $\mathrm{SiO}_{2}$ mol.\% addition, as indicated.

Figure 4 shows the surfaces of $1 \mathrm{~h}$ ball milled and sintered samples $(\mathrm{a}-\mathrm{c})$, and $3 \mathrm{~h}$ ball milled and sintered samples $(\mathrm{d}-\mathrm{f})$. The increasing planetary ball milling time decreases the particle size, which leads to smaller grains even at $1500^{\circ} \mathrm{C}$. The sintered relative density of samples increases by increasing ball milling time and also with increasing molar ratio of added $\mathrm{SiO}_{2}$. The increasing $\mathrm{SiO}_{2}$ molar fraction also decreases the particle size. $\mathrm{SiO}_{2}$ is acting as an interlayer phase-forming agent, as seen in Fig. $4 \mathrm{~d}-\mathrm{f}$.

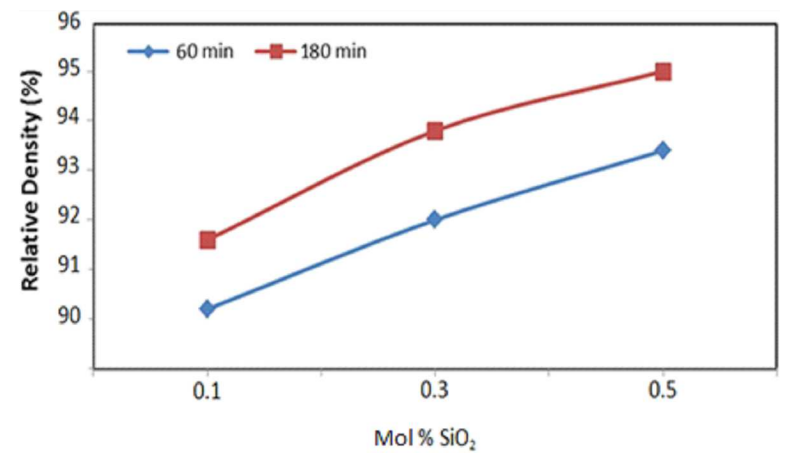

Fig. 5. The relative densities of sintered samples versus $\mathrm{SiO}_{2}$ fraction.
The relative densities of sintered samples, measured by Archimedes' rule of immersion in water, plotted vs $\mathrm{SiO}_{2}$ mol.\% fraction, for increasing ball milling time, can be seen in Fig. 5. As it was already seen in SEM images in Fig. 4, the relative density increases with ball milling time due to increasing number and volume of highly energetic particles. The $95 \%$ of relative density was achieved after $180 \mathrm{~min}$ of planetary ball milling, even for sintering at $1500^{\circ} \mathrm{C}$ for $4 \mathrm{~h}$, with increasing amount of $\mathrm{SiO}_{2}$, used as sintering aid. The impact and fracture energy applied to the powders was increased and the sintering neck formation was facilitated by higher specific surface area of particles, which has led to a decrease in sintering temperature with the increasing $\mathrm{SiO}_{2}$ content. From the sintering viewpoint, it can be thought that $\mathrm{SiO}_{2}$ addition had increased the liquid phase formation in a synergetic effect with planetary ball milling.

\section{Conclusions}

- The YAG phases were successfully produced via $3 \mathrm{~h}$ of planetary ball milling with the addition of $\mathrm{SiO}_{2}$.

- The sintering of YAG and related phases were evaluated by means of XRD and SEM, followed by relative density measurements by Archimedes' rule.

- Up to $95 \%$ of theoretical density were achieved after the densification of YAG samples, even at $1500^{\circ} \mathrm{C}$ after $4 \mathrm{~h}$ of ball milling. Phase formation was completed to some extent as YAG-YAP-YAM phases, with an average grain size of $450 \mathrm{~nm}$, have occurred.

\section{References}

[1] J. Lu, M. Prabhu, K. Ueda, H. Yagi, T. Yanagitani, A. Kudryashov, A.A. Kaminskii, Laser Phys. 11, 1053 (2001).

[2] L. Wen, X. Sun, Z. Xiu, S. Chen, C. Tsai, J. Europ. Ceram. Soc. 24, 2681 (2004).

[3] S. Bhattacharyya, T.K. Mukhopadhyay, K. Dana, S. Ghatak, Ceram. Int. 37, 3463 (2011).

[4] X. Chen, T. Lu, N. Wei, Z. Lu, W. Zhang, B. Ma, Y. Guan, W. Liu, F. Jiang, J. Alloy. Compd. 589, 448 (2014).

[5] M. Abdelkader, S.E. Alashry, Saudi J. Ophthalmol. 29, 116 (2015).

[6] D. Zhao, T.W. Coyle, K. Chien, Surf. Coat. Technol. 235, 303 (2013).

[7] A.M. Kutyin, E.Y. Rostokina, E.M. Gavrishchuk, V.V. Drobotenko, A.D. Plekhovich, P.A. Yunin, $C e-$ ram. Int. 41, 10616 (2015).

[8] G. Casalino, M. Mortello, P. Peyre, J. Mater. Proc. Technol. 223, 139 (2015).

[9] B. Liu, J. Li, M. Ivanov, W. Liu, J. Liu, T. Xie, S. Zhuo, Y. Pan, J. Guo, Optic. Mater. 36, 1591 (2014).

[10] K.E. Öksüz, F. Apaydın, A.E. Bozdă̆, M. Çevik, A. Özer, Proced. Mater. Sci. 11, 44 (2015). 